\title{
Problem-solving therapy for people who present to hospital with self-harm: Zelen randomised controlled trial
}

\author{
Simon Hatcher, Cynthia Sharon, Varsha Parag and Nicola Collins
}

\section{Background}

Presentations to hospital with self-harm are common, associated with suicide and have an increased mortality, yet there is no accepted effective intervention.

\begin{abstract}
Aims
To investigate whether problem-solving therapy would improve outcomes in adults presenting to hospital with self-harm, compared with usual care.
\end{abstract}

\section{Method}

A Zelen randomised controlled trial was conducted in four district health boards in New Zealand. A second hospital presentation with self-harm at 1 year for all episodes, plus separate comparisons of first-time and repeat presentations at the index episode, were the a priori primary outcomes. The trial registration number was ACTRN12605000337673.

\section{Results}

In an intention-to-treat analysis of all randomised patients $(n=1094)$ there was no significant difference at 12 months in the proportion of people who had presented again with selfharm when comparing all episodes (intervention 13.4\%, usual care $14.1 \%$; relative risk reduction $\mathrm{RR}=0.05,95 \% \mathrm{Cl}-0.28$ to $0.30, P=0.79)$ or where the index episode was the first episode (intervention $13.4 \%$, usual care $9.4 \%, R R=-0.42$, $95 \% \mathrm{Cl}-1.17$ to $0.08, P=0.37$ ). Where the index episode was repeated self-harm, those who received therapy were less likely to present again with self-harm (intervention $13.5 \%$, usual care $22.1 \%, \mathrm{RR}=0.39,95 \% \mathrm{Cl} 0.07$ to 0.60 , number needed to treat $12, P=0.03$ ).

\section{Conclusions}

Problem-solving therapy is not recommended for everyone who presents to hospital with self-harm. Among adults with a history of self-harm it may be an effective intervention.

\section{Declaration of interest}

None.
The problem of people presenting to hospital because of self-harm is important because the behaviour is common, ${ }^{1}$ it is linked to suicide, ${ }^{2}$ and there is a significant increase in premature mortality from other causes. ${ }^{3}$ From a public health perspective, people who are admitted to hospital with self-harm are an easily identifiable high-risk group who represent an important opportunity for intervention, particularly in relation to suicide prevention. Despite the importance of self-harm there is no generally accepted evidence-based intervention. Although there is limited evidence for the effectiveness of dialectical behaviour therapy in reducing self-harm in people with borderline personality disorder, the majority of people who present to hospital with self-harm do not have this diagnosis. ${ }^{4}$ Dialectical behaviour therapy also requires extensive training and is costly to deliver. Systematic reviews have indicated that problem-solving therapy is promising as an effective brief intervention for adults following self-harm. There is also evidence that many people who self-harm, especially those who present with self-harm to hospitals for the second or subsequent time, show poor problem-solving skills. ${ }^{6}$ Previous studies of cognitive-behavioural interventions have been in specific populations: those with recurrent self-harm, ${ }^{7}$ young people with multiple episodes, ${ }^{8}$ or in populations with high rates of repetition in the control group. ${ }^{9}$ The conclusions from these studies are qualified because of the small size of most trials, the populations studied being unrepresentative of people who self-harm and the absence of information about the acceptability of interventions. To overcome the problems of previous trials we decided to use a Zelen design, in which people are randomised before being asked for their consent, as this potentially recruits a larger, more representative study population, provides information about the acceptability of the intervention and implicitly takes into account patient preferences for treatment. ${ }^{10}$
We investigated whether, in people who presented to hospital with self-harm, problem-solving therapy compared with usual care reduced the proportion repeating self-harm within 12 months and improved measures of distress and suicidal risk at 3 months and 12 months.

\section{Method}

The study used a pragmatic double-consent Zelen design whereby potential participants were randomised to problem-solving therapy plus usual care or usual care alone. After the randomisation they were approached and asked for their consent to participate in whichever study arm they had been allocated to. Participants in the intervention arm were asked to consent to receive problem-solving therapy and complete follow-up measures at 3 months and at 1 year. Participants in the control arm were asked to consent to complete outcome measures at 3 months and at 1 year. Potential participants were not told about the other arm of the trial. To manage the ethical issues of a Zelen design, as well as to advise on other issues, we formed an advisory board which included clinicians, policy-makers, researchers from other universities and Maori representatives, which sat regularly before and during the study. The board members, especially the cultural representatives, were strongly supportive of the Zelen design. The trial was registered with the Australian New Zealand Clinical Trials Registry (www.anzctr.org.au), identifier ACTRN12605000337673.

\section{Setting}

The trial was conducted between September 2005 and June 2008 at four district health boards (DHBs) in New Zealand: North Shore Hospital, Waitakere Hospital (Waitemata DHB); Middlemore 
Hospital (Counties Manukau DHB); Whangarei Hospital (Northland DHB); Wellington Hospital and Kenepuru Hospitals (Capital and Coast DHB). These boards provide healthcare for about a third of the New Zealand population. Waitemata DHB provides health services for a population of about 525000 people in urban north and west Auckland and a rural area north of the city, with about $17 \%$ of its population living in the most deprived areas. Counties Manukau provides healthcare for 470000 people in the south of Auckland and serves a population that is relatively young with a high proportion of Maori and recent immigrants, with a third of the population living in areas that are very deprived (http://www.cmdhb.org.nz/about_cmdhb/ overview/population-profile.htm). Northland DHB serves a mainly rural area with a population of about 150000 , characterised by a large Maori population, dispersed rural communities and a high level of socio-economic deprivation. Capital and Coast DHB provides health services to 270000 persons, two-thirds of whom live in Wellington City and who constitute a relatively affluent population, with nearly a quarter of the population living in the least deprived areas.

\section{Participants}

Patients who presented to hospital after self-harm were eligible if they were not at school and were more than 16 years old; were not receiving dialectical behaviour therapy for borderline personality disorder or had a management plan which precluded having a short-term therapy; were not cognitively impaired; and had not been admitted to a psychiatric unit following the index presentation for longer than $48 \mathrm{~h}$. Patients who needed an interpreter were included in the study. Self-harm was defined as intentional self-poisoning or self-injury, irrespective of motivation. Self-poisoning included the intentional ingestion of more than the prescribed amount of any drug, whether or not there was evidence that the act was intended to result in death. This also included poisoning with non-ingestible substances (for example pesticides or carpet cleaner), overdoses of 'recreational' drugs and severe alcohol intoxication where the clinical staff considered such cases to be an act of self-harm. Self-injury was defined as any injury that had been intentionally self-inflicted.

\section{Randomisation and masking}

After the patient had received a psychosocial assessment from a mental health clinician and details of the assessment were available, a research therapist determined eligibility. If the patient had not received an assessment by a mental health professional the researchers read any available notes and discussed the presentation with S.H. or C.S. who decided eligibility. (In New Zealand it is national policy that everyone who presents to hospital with self-harm receives a psychosocial assessment from a mental health professional, and it was rare in the participating centres for people presenting with self-harm not to receive an assessment.) Eligible patients were randomised (1:1) using computer-generated random numbers (from an independent statistician) contained in sealed envelopes, stratified by centre, to receive either problem-solving therapy in addition to usual care or usual care alone. The research therapist then approached patients to ask for their consent to participate. The approach occurred either within the emergency department or, where necessary, by telephone after the patient was discharged. Researchers masked to treatment allocation subsequently interviewed consenting participants by telephone at 3 months and 1 year to ask about healthcare use and repeat self-harm that did and did not result in hospital contact.

\section{Interventions}

The intervention consisted of up to nine hour-long sessions of problem-solving therapy, which started as soon as practicable after the index episode and lasted for up to 3 months. The therapy was conducted with individual patients in out-patient clinics and was based on the model originally defined by D'Zurilla \& Goldfried. ${ }^{11}$ The steps included problem orientation, problem listing and definition, brainstorming, devising an action plan and reviewing the plan. Problem orientation is a person's approach to problems which varies from ignoring them and hoping they will go away (negative orientation) to seeing them as opportunities and challenges to do things differently (positive orientation). We also paid attention to engaging people by getting them to tell the story of their attempt and understanding the motivation behind it. We made regular risk assessments and in the final sessions asked participants to apply their new skills to the circumstances around their original self-harm attempt. A therapist manual and client workbook were designed by the study team and used throughout the study. The manuals, client workbooks, training videos plus further information on the therapy are available to download from our website www.tractusgroup.ac.nz.

Before the study we decided that a minimum of four sessions were needed to complete the problem-solving therapy, which allowed time for at least one problem-solving cycle and the application of new skills to the original attempt. The clinicians who delivered the therapy were recruited specifically for the study and received 1 week of training in problem-solving therapy from S.H. and C.S. The therapists did not have extensive experience of working in mental health settings and came from a variety of backgrounds including social work, psychotherapy, counselling and health psychology. They received weekly group supervision and fortnightly individual supervision from S.H. and C.S.

Usual care following self-harm varies and may involve referral to multidisciplinary teams for psychiatric or psychological intervention, referral to mental health crisis teams, recommendations for engagement with alcohol and drug treatment centres or other health and non-health services. We recorded usual care for all patients who consented to follow-up in the control and intervention groups.

\section{Measures}

The primary outcome was presentation to hospital with self-harm in the year after the index attempt. We planned before the study started (as an a priori hypothesis) to analyse the data for those who had attended for the first time with this problem separately from those who had presented on more than one occasion on this outcome measure, as a history of self-harm is the best predictor of repetition, those who repeatedly attend with self-harm have poorer problem-solving skills, ${ }^{6}$ and people who repeatedly selfharm make up about half of all presentations of self-harm to hospital. ${ }^{12}$ For the secondary outcomes we chose measures that assessed areas recommended in the National Institute for Health and Clinical Excellence guidelines on the assessment of self-harm: hopelessness, depression, suicidal ideas and problem-solving. ${ }^{13}$ The secondary outcomes were assessed at 3 months and 1 year after the index attempt for all patients who consented to participate. Measures included the self-rated Beck Hopelessness Scale (BHS) total score; the self-rated Beck Scale for Suicide Ideation (BSIS) total score; the self-rated Hospital Anxiety and Depression Scale (HADS) depression and anxiety symptoms subscales; the self-rated Social Problem Solving Inventory Revised (SPSI-R) total score, where low scores indicate poorer problem-solving; and self-reported repetition of self-harm. ${ }^{14-17}$ We also planned to analyse the proportion of patients with a total 
BHS score of 9 or over at baseline, 3 months and 1 year. (We chose this cut-off as previous work has shown that patients scoring 9 or above are nearly 11 times more likely to die subsequently by suicide or to self-harm compared with those who score below this threshold. $)^{18}$

Participants completed the questionnaires at enrolment into the study, at 3 months and at 1 year and were asked to return them to the researchers. For all randomised participants we obtained from the New Zealand Health Information Service details of hospital contacts throughout New Zealand in the year after the index attempt to assess repetition of self-harm and hospital use. The data were obtained from the National Minimum Dataset kept by the New Zealand health information service (http:// www.moh.govt.nz/moh.nsf/indexmh/dataandstatistics-collectionsnmds), which contains routinely collected information on all public and private hospital discharges in New Zealand.

For the primary outcome we could obtain information on repetition of self-harm for everyone who was randomised, so the analysis of repetition of self-harm is a true intention-to-treat analysis but has the advantage over conventional randomised controlled trials in that it also includes those who refused to take part. For the analysis of secondary outcomes we used data from just those people who consented to take part in the study and we have called this a per protocol analysis.

\section{Power calculation}

For calculation of power the primary end-point was another presentation to hospital within 12 months of the index episode in an intention-to-treat analysis regardless of consent. Assuming a $16 \%$ rate of hospital re-presentation in the usual care group, ${ }^{2}$ and a $10 \%$ repetition rate in the therapy group, we calculated that we would need to randomise 521 people into each arm of the study with $80 \%$ power (two-tailed test, level of significance $P<0.05)$. The secondary end-point was the Beck Hopelessness Scale score which typically has a standard deviation of four units. We calculated that we would need 500 people to consent to completion of questionnaires to detect a change in mean BHS scores at 12 months of one unit with $80 \%$ power (two-tailed test, $P<0.05)$.

\section{Statistical analysis}

All statistical analyses were performed using SAS version 9.1 for Windows (SAS Institute, Cary, North Carolina, USA). All statistical tests were two-tailed. Differences in baseline characteristics between the treatment groups were compared using $t$-tests or analyses of variance for continuous variables and chi-squared tests for categorical variables. The number of patients repeating selfharm was compared between the treatment groups using logistic regression. Time to first re-presentation was compared between the treatment groups using Cox proportional hazards regression. The interaction between treatment groups and whether the index episode was a first or repeat presentation were tested for all repetition of self-harm outcomes. Each of the continuous outcomes measured (at 3 months and 1 year) were analysed using repeated mixed models regression with an unstructured covariance structure and adjusted for baseline value of the measure. Data for participants with both 3-month and 1-year outcomes missing were excluded from these analyses. Analyses were also conducted adjusting for the clustering effect of hospital and therapist. The proportion of patients with a total BHS score of 9 or above in each intervention group was analysed using logistic regression and adjusted for baseline total BHS score of 9 or above.
All analyses were conducted using data from patients who were randomised and had consented to participate, irrespective of compliance with the intervention, except for the primary outcome which was an intention-to-treat analysis that included all eligible randomised patients regardless of whether they consented to take part in the study.

\section{Results}

Figure 1 shows the flow of participants through the trial. Table 1 shows the baseline characteristics of patients by treatment and consent. There was no significant difference between the patients who consented to problem-solving therapy or usual care. However, the patients who refused consent were more likely to be presenting for the first time and less likely to be of New Zealand European ethnicity than those who consented. At baseline patients presenting for a first episode had a significantly greater positive problem orientation than those attending for repeated self-harm (mean total SPSI-R score 84.5 , s.d. $=16.6, n=301$ in first-time attenders v. 78.5, s.d. $=16.3, n=241$ in repeat attenders; $P<0.001)$.

People presenting to hospital with self-harm assessed for eligibility $n=2025$

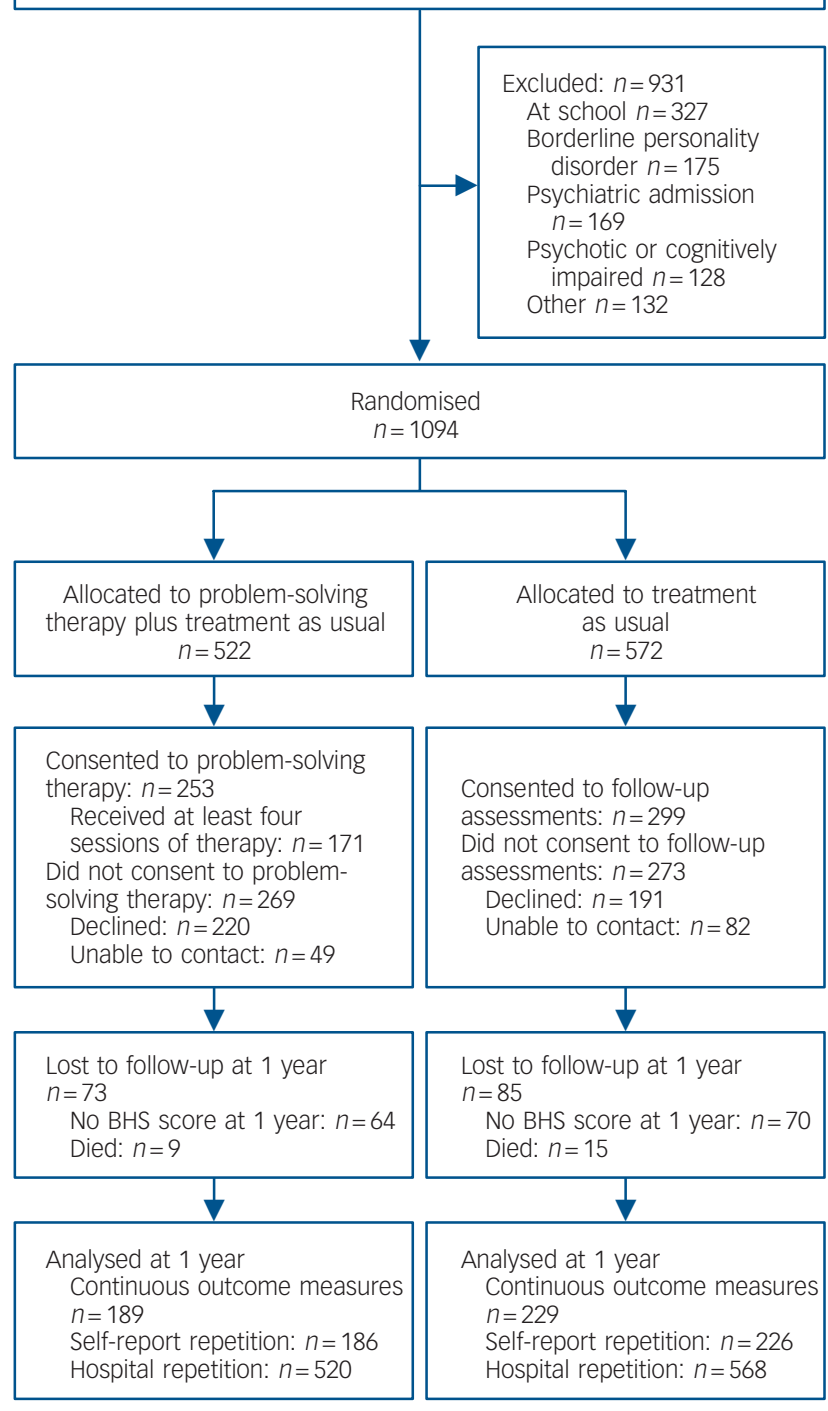

Fig 1 Flow diagram of progress through trial (BHS, Beck Hopelessness Scale score). 


\begin{tabular}{|c|c|c|c|c|c|c|}
\hline & \multicolumn{2}{|c|}{ Patients randomised and consenting } & \multirow{2}{*}{$\begin{array}{l}\text { Difference } \\
\text { between } \\
\text { consenting } \\
\text { groups } \\
P\end{array}$} & \multicolumn{2}{|c|}{ Patients randomised who refused consent } & \multirow{2}{*}{$\begin{array}{l}\text { Difference } \\
\text { between } \\
\text { consenting and } \\
\text { refusal groups } \\
P\end{array}$} \\
\hline & $\begin{array}{c}\text { PST plus TAU } \\
n=253\end{array}$ & $\begin{array}{c}\text { TAU } \\
n=299\end{array}$ & & $\begin{array}{c}\text { PST } \\
n=269\end{array}$ & $\begin{array}{c}\text { TAU } \\
n=273\end{array}$ & \\
\hline Age, years: mean (s.d.) & $33.2(12.5)$ & $34.2(13.2)$ & 0.34 & $32.3(13.8)$ & $33.2(13.8)$ & 0.39 \\
\hline Gender: female, $n$ (\%) & $173(68)$ & $207(69)$ & 0.83 & $185(69)$ & $171(63)$ & 0.34 \\
\hline $\begin{array}{l}\text { Ethnicity, } n \text { (\%) } \\
\text { NZ European } \\
\text { Maori } \\
\text { Pacific Island } \\
\text { Asian } \\
\text { Other }\end{array}$ & $\begin{array}{c}157(62) \\
36(14) \\
18(7) \\
5(2) \\
37(15)\end{array}$ & $\begin{array}{c}179(60) \\
52(17) \\
16(5) \\
12(4) \\
40(13)\end{array}$ & 0.45 & $\begin{array}{l}120(45) \\
51(19) \\
45(17) \\
25(9) \\
28(10)\end{array}$ & $\begin{array}{r}111(41) \\
59(22) \\
32(12) \\
28(10) \\
43(16)\end{array}$ & $<0.0001$ \\
\hline Lives alone, $n(\%)$ & $28(11)$ & $37(12)$ & 0.63 & $32(12)$ & $22(8)$ & 0.37 \\
\hline First self-harm, $n(\%)$ & $136(54)$ & $169(57)$ & 0.49 & $177(66)$ & $191(70)$ & 0.0002 \\
\hline \multicolumn{7}{|l|}{ Type of self-harm, $n$ (\%) } \\
\hline $\begin{array}{l}\text { Overdose } \\
\text { Carbon monoxide }\end{array}$ & $208(82)$ & $239(80)$ & 0.50 & $203(76)$ & $204(75)$ & 0.11 \\
\hline poisoning & $11(4)$ & $13(4)$ & 1.00 & $12(5)$ & 7 (3) & 0.61 \\
\hline Cutting & $32(13)$ & $34(11)$ & 0.65 & $32(12)$ & $46(17)$ & 0.20 \\
\hline Hanging & $9(4)$ & $6(2)$ & 0.26 & $15(6)$ & $12(4)$ & 0.15 \\
\hline
\end{tabular}

Table 2 shows self-reported usual care from the telephone interviews for the two groups. Most follow-up occurred in primary care and most people did not receive any face-to-face contact with mental health services. Participants who consented to problem-solving therapy had received significantly fewer mental health contacts after 3 months compared with those who consented to usual care. Participants who consented to problem-solving therapy received a mean of 5.12 sessions (median 6 , s.d. $=2.9$, range 0-9). Twenty-five persons consented to problem-solving therapy but did not attend any sessions (their data are included in all analyses) and 171 participants received at least four sessions.

\section{Primary outcomes}

Table 3 shows the number of people repeating self-harm within a year of their index attempt (both hospital presentations and self-reported self-harm), as well as the time to repetition for hospital presentation. There was no significant difference between groups when comparing all episodes. After a year there had been
120 hospital presentations of self-harm in those randomised to problem-solving therapy and 124 episodes in the usual care group.

The interaction between treatment groups and whether the index episode was a first or repeated episode were significant for all self-harm outcomes $(P<0.01)$. For patients whose index episode was the first presentation for self-harm there was no significant difference between the groups. However, for patients whose index episode was a repeat presentation, those who received problem-solving therapy compared with those who had usual care were less likely to present again to hospital with self-harm after a year (intention-to-treat analysis relative risk reduction $0.39,95 \%$ CI $0.07-0.60$, number needed to treat $12, P=0.03$ ). Also for patients whose index episode was a repeat presentation, those allocated to therapy had a significantly shorter time to repetition compared with usual care (intention-to-treat analysis for re-presentation to hospital, hazard ratio $0.58,95 \%$ CI $0.36-0.94, P=0.03$ ). This finding was consistent for hospital re-presentations, self-reported self-harm and a per protocol analysis comparing patients who had given consent.

Table 2 Self-reported use of health services at 3 months and 12 months

\begin{tabular}{|c|c|c|c|c|}
\hline & \multicolumn{2}{|c|}{ Problem-solving therapy group $n=253$} & \multicolumn{2}{|c|}{ Treatment as usual group $n=299$} \\
\hline & $\begin{array}{l}\text { Index episode } \\
\text { to } 3 \text { months } \\
\quad n=218\end{array}$ & $\begin{array}{c}\text { From } \\
3 \text { to } 12 \text { months } \\
n=183\end{array}$ & $\begin{array}{l}\text { Index episode } \\
\text { to } 3 \text { months } \\
\quad n=240\end{array}$ & $\begin{array}{c}\text { From } \\
3 \text { to } \begin{array}{c}12 \text { months } \\
n=205\end{array}\end{array}$ \\
\hline Number of GP contacts: mean (s.d.) ${ }^{a}$ & $1.59(1.8)$ & $4.6(5.9)$ & $1.70(2.2)$ & $4.5(5.2)$ \\
\hline Patients who attended a GP, $n$ (\%) & $152(68)$ & $173(82)$ & $164(62)$ & $199(82)$ \\
\hline Number of community mental health centre contacts: mean (s.d.) & $1.00(3.2)$ & $1.4(5.4)$ & $1.6(4.7)$ & $2.6(10.7)$ \\
\hline Patients who attended a community mental health centre, $n(\%)$ & $57(26)$ & $48(26)$ & $88(37)^{\star b}$ & $54(26)$ \\
\hline Patients who reported no mental health follow-up, $n(\%)$ & $96(44)$ & $94(51)$ & $82(34)^{\star c}$ & $92(45)$ \\
\hline \multirow[t]{2}{*}{ People admitted to a general hospital after 1 year, $n(\%)$} & & $83(33)$ & & $84(28)$ \\
\hline & & $n=253$ & & $n=299$ \\
\hline \multirow[t]{2}{*}{ People admitted to a psychiatric hospital after 1 year, $n(\%)$} & & $11(4)$ & & $19(6)$ \\
\hline & & $n=253$ & & $n=299$ \\
\hline \multicolumn{5}{|c|}{$\begin{array}{l}* P<0.05 \text {. } \\
\text { GP, general practitioner. } \\
\text { a. All contacts are face-to-face. Median value for all contacts in both groups is } 0 \text { at both time points except for number of GP contacts, where the median is } 1 \text { in both groups } \\
\text { at } 3 \text { months and } 3 \text { in both groups at } 3-12 \text { months. } \\
\text { b. } P=0.02 \text {, problem-solving group } v \text {. treatment as usual group at } 3 \text { months, } \chi^{2} \text {-test. } \\
\text { c. } P=0.04 \text {, problem-solving group } v \text {. treatment as usual group at } 3 \text { months, } \chi^{2} \text {-test. }\end{array}$} \\
\hline
\end{tabular}


Table 3 Repetition of self-harm and time to repetition at 1 year after index presentation

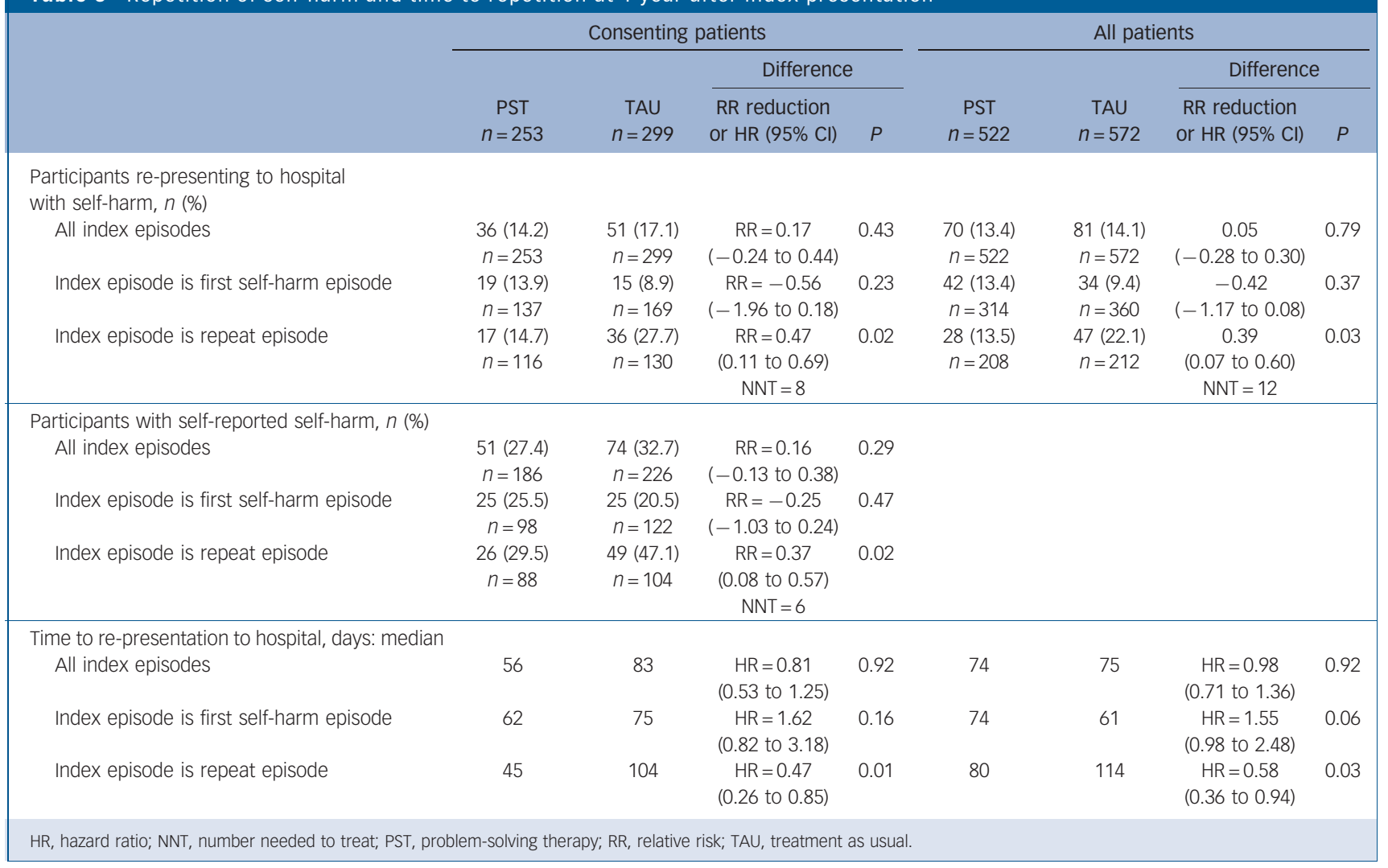

\section{Secondary outcomes}

Table 4 shows the mean scores for both groups and the difference between the groups for each of the continuous outcomes at 3 months and at 1 year. All continuous outcome measures were missing at both follow-up points for 67 participants (12.1\%), whose data are excluded from this analysis. Individuals who were missing continuous outcome data were more likely to be male (49.3\% v. 28.7\%, $P=0.003)$, not of New Zealand European ethnicity $(59.7 \%$ v. $38 \%, P<0.0001)$ and have a lower baseline BHS score $(8.4 v .10 .9, P=0.0025)$ than those not missing data. After a year participants in the problem-solving therapy group showed a statistically significant greater change from baseline on all outcome measures. Adjusting for centre and therapist made no difference to these results.

At baseline the proportion of people with a BHS score of 9 or greater was $66 \%$ (156 of 238 people) in the problem-solving therapy group and $52 \%$ (149 of 284 people) in the usual care group. At 3 months and 1 year the proportion of patients with a BHS score of 9 or over in each group was significantly less in the therapy group compared with the usual care group (odds ratio at 3 months $0.24,95 \%$ CI $0.15-0.39, P<0.001$; at 1 year $\mathrm{OR}=0.62,95 \%$ CI $0.40-0.96, P=0.03$ ).

To assess whether there was a dose-response relationship between the amount of problem-solving therapy and change on the continuous outcome measures we performed two secondary analyses. First, we analysed separately data for people who had completed four or more sessions of therapy and compared them with participants who had received usual care (Table 4). The difference increased to 2.9 points on the BHS after a year and the change in other scores was greater for all continuous outcome measures. Second, we compared those who had completed four or more sessions of therapy $(n=171)$ with those who had attended three sessions or fewer $(n=82)$. This showed that those who had completed therapy had significantly greater changes on problem-solving (difference $-7.6,95 \%$ CI -12.5 to -2.6 , $P=0.003$ ), anxiety (difference $1.7,95 \%$ CI 0.4 to $3.0, P=0.01$ ) and depression (difference $1.5,95 \%$ CI 0.2 to $2.7, P=0.02$ ) at 3 months and in hopelessness (difference $2.1,95 \%$ CI 0.4 to 3.8 , $P=0.02$ ) and depression (difference $1.7,95 \%$ CI 0.3 to 3.2 , $P=0.02$ ) at 1 year compared with those who did not attend at least four sessions.

\section{Discussion}

We found that in people presenting to hospital with self-harm, problem-solving therapy had little effect on the overall repetition rate at 1 year. However, in a planned secondary analysis of the $38 \%$ of people who presented with a repeat episode of self-harm, those randomised to therapy had a 39\% lower risk of a further presentation after a year. In this group those who did present again did so significantly earlier if they had received problemsolving therapy compared with usual care. The study also found that patients consenting to this therapy had significantly greater improvements at 3 months and 1 year in measures of hopelessness, suicidal thinking, problem-solving, anxiety and depression. A secondary analysis to assess whether there was a dose-response relationship between the amount of therapy and the size of change found that patients who completed four or more sessions had better outcomes than those who had fewer sessions.

Our finding that problem-solving deficits were greater (a lower score on the SPSI-R) in those whose index episode was repeated self-harm than in first-time patients is similar to that of other authors, ${ }^{19}$ and may explain why problem-solving therapy is more effective for preventing repetition in the former group. The finding that those with repeated self-harm who received 
Table 4 Continuous outcome measure scores at 3 months, 1 year and mixed-model results for difference in scores between treatments at follow-up

\begin{tabular}{|c|c|c|c|c|c|}
\hline & \multirow[b]{2}{*}{$\begin{array}{l}\text { All patients } \\
\text { consenting to } \\
\text { PST, } n=253 \\
\text { Mean (s.d.) }\end{array}$} & \multirow[b]{2}{*}{$\begin{array}{c}\text { Patients who } \\
\text { completed } \geqslant 4 \text { sessions } \\
\text { of PST, } n=171 \\
\text { Mean (s.d.) }\end{array}$} & \multirow[b]{2}{*}{$\begin{array}{l}\text { Patients who } \\
\text { received TAU } \\
\text { alone, } n=299 \\
\text { Mean (s.d.) }\end{array}$} & \multicolumn{2}{|c|}{ Difference } \\
\hline & & & & $\begin{array}{l}\text { All patients } \\
\text { consenting } \\
\text { to PST and TAU } \\
\text { Mean }(95 \% \mathrm{Cl})\end{array}$ & $\begin{array}{l}\text { Patients completing } \\
\geqslant 4 \text { sessions of PST } \\
\text { and TAU } \\
\text { Mean }(95 \% \mathrm{Cl})\end{array}$ \\
\hline \multicolumn{6}{|c|}{ Beck Hopelessness Scale } \\
\hline Baseline & $\begin{array}{c}11.5(5.8) \\
n=251\end{array}$ & $\begin{array}{c}11.9(5.7) \\
n=171\end{array}$ & $\begin{array}{c}10.2(6.5) \\
n=294\end{array}$ & & \\
\hline Three months & $\begin{array}{l}5.7(5.5) \\
n=193\end{array}$ & $\begin{array}{l}5.3(5.4) \\
n=147\end{array}$ & $\begin{array}{l}8.9(6.6) \\
n=226\end{array}$ & $3.5(2.6 \text { to } 4.5)^{* *}$ & $3.9(2.9 \text { to } 5.0)^{\star *}$ \\
\hline One year & $\begin{array}{l}5.8(5.8) \\
n=189\end{array}$ & $\begin{array}{l}5.4(5.5) \\
n=144\end{array}$ & $\begin{array}{l}7.2(6.4) \\
n=229\end{array}$ & $2.3(1.2 \text { to } 3.4)^{\star *}$ & $2.9(1.8 \text { to } 4.0)^{\star *}$ \\
\hline \multicolumn{6}{|c|}{ Beck Suicide Ideation Scale } \\
\hline Baseline & $\begin{array}{c}11.3(9.2) \\
n=253\end{array}$ & $\begin{array}{c}12.0(9.3) \\
n=170\end{array}$ & $\begin{array}{c}10.9(9.9) \\
n=296\end{array}$ & & \\
\hline Three months & $\begin{array}{l}3.7(6.8) \\
n=194\end{array}$ & $\begin{array}{l}3.9(7.0) \\
n=148\end{array}$ & $\begin{array}{l}7.1(8.6) \\
n=230\end{array}$ & $3.3(2.1 \text { to } 4.6)^{\star *}$ & $3.5(2.2 \text { to } 4.9)^{\star \star *}$ \\
\hline One year & $\begin{array}{l}3.7(6.7) \\
n=187\end{array}$ & $\begin{array}{l}3.6(7.0) \\
n=143\end{array}$ & $\begin{array}{l}4.8(7.4) \\
n=231\end{array}$ & $1.6(0.3 \text { to } 2.9)^{* a}$ & $1.9(0.5 \text { to } 3.2)^{\star b}$ \\
\hline \multicolumn{6}{|c|}{ Social Problem-Solving Inventory Scale } \\
\hline Baseline & $\begin{array}{c}81.2(16.2) \\
n=249\end{array}$ & $\begin{array}{c}80.8(16.4) \\
n=170\end{array}$ & $\begin{array}{c}82.6(17.1) \\
n=296\end{array}$ & & \\
\hline Three months & $\begin{array}{c}95.2(18.3) \\
n=196\end{array}$ & $\begin{array}{c}96.9(18.4) \\
n=150\end{array}$ & $\begin{array}{c}85.4(19.5) \\
n=228\end{array}$ & $-11.1(-13.9 \text { to }-8.3)^{\star \star}$ & $-12.9(-15.9 \text { to }-9.9)^{\star *}$ \\
\hline One year & $\begin{array}{c}92.2(18.1) \\
n=190\end{array}$ & $\begin{array}{c}92.9(18.2) \\
n=146\end{array}$ & $\begin{array}{c}90.5(18.9) \\
n=233\end{array}$ & $-4.2(-7.2 \text { to }-1.3)^{\star b}$ & $-5.1(-8.4 \text { to }-1.9)^{\star *}$ \\
\hline \multicolumn{6}{|c|}{ HADS anxiety subscale } \\
\hline Baseline & $\begin{array}{c}13.0(4.3) \\
n=251\end{array}$ & $\begin{array}{c}13.1(4.2) \\
n=171\end{array}$ & $\begin{array}{c}12.4(4.6) \\
n=295\end{array}$ & & \\
\hline Three months & $\begin{array}{l}8.6(4.4) \\
n=196\end{array}$ & $\begin{array}{l}8.2(3.9) \\
n=150\end{array}$ & $\begin{array}{c}10.6(5.2) \\
n=230\end{array}$ & $2.3(1.5 \text { to } 3.1)^{\star *}$ & $2.7(1.9 \text { to } 3.5)^{\star *}$ \\
\hline One year & $\begin{array}{l}9.2(4.4) \\
n=190\end{array}$ & $\begin{array}{l}9.0(4.3) \\
n=146\end{array}$ & $\begin{array}{l}9.5(5.0) \\
n=232\end{array}$ & $1.0(0.2 \text { to } 1.8)^{\star b}$ & $1.3(0.4 \text { to } 2.2)^{\star *}$ \\
\hline \multicolumn{6}{|c|}{ HADS depression subscale } \\
\hline Baseline & $\begin{array}{c}10.0(4.3) \\
n=251\end{array}$ & $\begin{array}{c}10.3(4.4) \\
n=171\end{array}$ & $\begin{array}{l}9.6(4.8) \\
n=295\end{array}$ & & \\
\hline Three months & $\begin{array}{l}5.2(4.3) \\
n=196\end{array}$ & $\begin{array}{l}5.0(4.1) \\
n=150\end{array}$ & $\begin{array}{l}7.5(5.1) \\
n=230\end{array}$ & $2.4(1.7 \text { to } 3.2)^{\star *}$ & $2.8(2.0 \text { to } 3.6)^{\star *}$ \\
\hline One year & $\begin{array}{l}5.3(4.7) \\
n=190\end{array}$ & $\begin{array}{l}5.0(4.6) \\
n=146\end{array}$ & $\begin{array}{l}6.2(4.8) \\
n=232\end{array}$ & $1.4(0.6 \text { to } 2.3)^{\star *}$ & $1.9(0.9 \text { to } 2.8)^{\star *}$ \\
\hline
\end{tabular}

problem-solving therapy were likely to present again earlier than those receiving usual care is explained by the fact that once this group had started the therapy they were unlikely to present again, so that most re-presentations occurred before the start of therapy or in the first few sessions.

Participants who received problem-solving therapy had significantly greater changes in all the continuous outcome measures at 1 year. The BHS has been established as an important measure of risk for suicide and self-harm in hospital and outpatient settings, ${ }^{20}$ and the use of this scale is recommended in guidelines on the assessment and management of people who are suicidal. The change of 2.3 points represents about a $30 \%$ relative improvement in hopelessness scores after a year in the problem-solving therapy group compared with the usual care group and is similar to that distinguishing suicidal from nonsuicidal older people. ${ }^{21}$ Moreover, at 1 year the proportion of people at high risk of further self-harm (BHS score $\geqslant 9$ ) was significantly lower in the group receiving problem-solving therapy than in those receiving usual care. The changes in suicidal intent, depression and anxiety were all statistically significantly greater in the problem-solving therapy group at both 3 months and 1 year, but their clinical significance at 1 year is probably limited. For the continuous outcome measures there were missing data for about one in eight participants. This is a limitation on the interpretation of the continuous outcome measures, but it is less than in previous papers in this area. ${ }^{22}$

\section{Strengths and limitations of the study}

The strength of the study is that it was a large pragmatic trial that managed to achieve a high proportion of people in treatment and had $100 \%$ follow-up of hospital re-presentations. The intentionto-treat analysis of hospital re-presentations included everybody randomised regardless of consent, so is an improvement on conventional randomised trials that do not tell the reader anything about people who choose not to receive the intervention. The main disadvantage of Zelen trials is in their analysis and interpretation when doing a per protocol analysis. First, there is the problem - shared with conventional randomised controlled trials - of external validity, because not everyone who is randomised consents to take part, which may produce trials of limited relevance. External validity may be less problematic in Zelen trials because a larger proportion of eligible people may be recruited, given the less complex consent process. Second, the 
process of asking for consent to the intervention or follow-up after randomisation reintroduces some selection bias, in that people who consent to the two arms might be different from one another in some way. However, this bias is important because it conveys information about the acceptability of the treatment and the effect of the treatment in those people who choose this therapy. This is not the case in conventional randomised trials, where potential participants are asked to consent to randomisation rather than to consent to receive a treatment or follow-up, which although good for internal validity may result in studies that are of little relevance to clinicians or policy-makers. In this trial people who consented to problem-solving therapy had poorer prognostic markers (higher scores on all continuous measures except the SPSI-R at baseline) than those who consented to usual care. Therefore, the direction of bias introduced by the Zelen process is likely to reduce any difference in the per protocol analyses between the treatments, thus making any significant differences more believable.

\section{Comparison with other studies}

Compared with previous studies, ${ }^{7,8}$ our study had broad inclusion criteria and the rate of repetition in the usual care group was similar to that in other broadly defined populations of people who present to hospital with self-harm. ${ }^{2}$ In a study of people who presented with repeat episodes of self-harm, manual-assisted cognitive therapy had no significant effect on the proportion of people who repeated; however, in that study four out of ten patients allocated to cognitive therapy did not receive any faceto-face treatment and the emphasis of the therapy was not on problem-solving. $^{7}$

\section{Implications}

Problem-solving therapy cannot be recommended as a standard treatment in all cases of self-harm. It may, however, be an effective intervention for people whose episode is a repeat attempt. Further research is needed on the cost-effectiveness of interventions after self-harm, on interventions in people who present with self-harm for the first time, and on combining potentially useful treatments such as the routine use of follow-up postcards with problem-solving therapy. ${ }^{23}$

Simon Hatcher, MD, Cynthia Sharon, MSC, Department of Psychological Medicine Faculty of Medical and Health Sciences, University of Auckland; Varsha Parag, MSc, Clinical Trials Research Unit, School of Population Health, University of Auckland; Nicola Collins, Department of Psychological Medicine, Faculty of Medical and Health Sciences, University of Auckland, Auckland, New Zealand

Correspondence: Simon Hatcher, Department of Psychological Medicine, Faculty of Medical and Health Sciences, University of Auckland, Private Bag 92019, Auckland, New Zealand. Email: s.hatcher@auckland.ac.nz

First received 28 Nov 2010, final revision 25 Mar 2011, accepted 26 May 2011

\section{Funding}

\section{The study was funded by the Accident Compensation Corporation of New Zealand.}

\section{Acknowledgements}

We thank the patients and staff of the four hospitals for their time and contribution to this study.

\section{References}

1 Hawton K, Harriss L, Hall S, Simkin S, Bale E, Bond A. Deliberate self-harm in Oxford, 1990-2000: a time of change in patient characteristics. Psychol Med 2003; 33: 987-95.

2 Owens D, Horrocks J, House A. Fatal and non-fatal repetition of self-harm: systematic review. Br J Psychiatry 2002; 181: 193-9.

3 Ostamo A, Lonnqvist J. Excess mortality of suicide attempters. SoC Psychiatry Psychiatr Epidemiol 2001; 36: 29.

4 Caihol L, Damsa C, Bui E, Klein R, Adam E, Schmitt L, et al. Is assessing for borderline personality disorder useful in the referral after a suicide attempt? [in French]. Encephale 2008; 34: 23-30.

5 Hawton K, Townsend E, Arensman E, Gunnell D, Hazell P, House A, et al. Psychosocial versus pharmacological treatments for deliberate self harm. Cochrane Database Syst Rev 2000; issue 2: CD001764.

6 Pollock LR, Williams JM. Problem-solving in suicide attempters. Psychol Med 2004; 34: 163-7.

7 Tyrer P, Thompson S, Schmidt U, Jones V, Knapp M, Davidson K, et al. Randomized controlled trial of brief cognitive behaviour therapy versus treatment as usual in recurrent deliberate self-harm: the POPMACT study. Psychol Med 2003; 33: 969-76.

8 Slee N, Garnefski N, van der Leeden R, Arensman E, Spinhoven P. Cognitive-behavioural intervention for self-harm: randomised controlled trial. Br J Psychiatry 2008; 192: 202-11.

9 Brown GK, Ten Have T, Henriques GR, Xie SX, Hollander JE, Beck AT. Cognitive therapy for the prevention of suicide attempts: a randomized controlled trial. JAMA 2005; 294: 563-70.

10 Zelen M. Randomized consent designs for clinical trials: an update. Stat Med 1990; 9: 645-56.

11 D'Zurilla TJ, Goldfried MR. Problem solving and behaviour modification. J Abnorm Psychol 1971; 78: 107-26.

12 Haw C, Bergen H, Casey D, Hawton K. Repetition of deliberate self-harm: a study of the characteristics and subsequent deaths in patients presenting to a general hospital according to extent of repetition. Suicide Life Threat Behav 2007; 37: 379-96.

13 National Institute for Health and Clinical Excellence. Self-Harm: The ShortTerm Physical and Psychological Management and Secondary Prevention of Self-Harm in Primary and Secondary Care. Clinical Guidelines CG16. NICE, 2004.

14 Beck AT, Weissman A, Lester D, Trexler L. The measurement of pessimism: the Hopelessness Scale. J Consult Clin Psychol 1974; 42: 861-5.

15 Beck A, Kovacs M, Weissman A. Assessment of suicide intention: the scale for suicide ideation. J Consult Clin Psychol 1979; 47: 343-52.

16 Zigmond A, Snaith R. The hospital anxiety and depression scale. Acta Psychiatr Scand 1983; 67: 361-70.

17 D'Zurilla TJ, Nezu AM, Maydeu-Olivares A. Manual for the Social Problem-Solving Inventory - Revised (SPSI-R). Multi-Health Systems, 1996.

18 McMillan D, Gilbody S, Beresford E, Neilly LIZ. Can we predict suicide and non-fatal self-harm with the Beck Hopelessness Scale? A meta-analysis. Psychol Med 2007; 37: 769-78.

19 McAuliffe C, Corcoran P, Keeley HS, Arensman E, Bille-Brahe U, De Leo D, et al. Problem-solving ability and repetition of deliberate self-harm: a multicentre study. Psychol Med 2006; 36: 45-55.

20 Beck AT, Brown G, Berchick RJ, Stewart BL, Steer RA. Relationship between hopelessness and ultimate suicide: a replication with psychiatric outpatients. Am J Psychiatry 1990; 147: 190-5.

21 Szanto K, Mulsant BH, Houck PR, Miller MD, Mazumdar S, Reynolds CF. Treatment outcome in suicidal vs. non-suicidal elderly patients. Am J Geriatr Psychiatry 2001; 9: 261-8.

22 Vaiva G, Ducrocq F, Meyer P, Mathieu D, Philippe A, Libersa C, et al. Effect of telephone contact on further suicide attempts in patients discharged from an emergency department: randomised controlled study. BMJ 2006; 332: 1241-5.

23 Carter G, Clover K, Whyte I, Dawson A, D'Este C. Postcards from the EDge project: randomised controlled trial of an intervention using postcards to reduce repetition of hospital treated deliberate self poisoning. BMJ 2005; 331: $805-10$ 